\title{
"Cuidaniños", intruso, mandadero: representaciones de la práctica de formación profesional
}

\author{
"Babysitter", Intruder, Office Boy: \\ Representations of the Professional Formation Practice
}

Pedro Baquero M.*

Recibido: $1 .^{\circ}$ de agosto de 2012

Wilmer Villa A.**

Aceptado: 22 de septiembre de 2012

\section{Resumen}

El presente artículo es producto de la investigación "Representaciones de la práctica de formación profesional". La investigación se ocupa del análisis de las representaciones sobre la práctica pedagógica o práctica docente, a partir del estudio de caso múltiple en cuatro programas de formación de licenciados en Educación, de la Universidad Distrital. El corpus analizado corresponde a formularios de encuesta, entrevistas semiestructuradas, narrativas y artefactos recogidos entre practicantes y profesores de práctica. Los datos se procesaron mediante técnicas de análisis de contenido y matrices semánticas.

El cometido es, de una parte, hacer visible lo que sienten y piensan los profesores en formación y sus asesores respecto de ese momento crucial de su trayectoria formativa que constituyen las prácticas docentes o prácticas pedagógicas; y de otra, volver la mirada sobre el orden institucional y político de los discursos y acciones que movilizan desde la universidad y la escuela las pretensiones formativas de los programas académicos.

Palabras clave: formación docente, práctica pedagógica, practicante, representación.

\section{Abstract}

The following paper is based on the research "Representations of the professional training practice. The focus of the study is the representations about the teaching praxis analysis. A Multiple case study was conducted in four programs of teaching formation at the Universidad Distrital. The analyzed corpus comes from interviews forms, semistructred interviews, narratives, artifacts, which were collected among internship teachers and their professors. Data was processed using content analysis and semantic matrix techniques. The main topics are, on one hand, making visible what student teachers and their professors feel and think about that crucial stage in their forming career, which later on will conform the teaching praxis. On the other hand, the study addresses the insight into the institutional and political order of the discourses and actions that are being promoted from the university, and moreover, what are the formative pretentions from the academic programs.

Key words: teaching formation, teaching praxis, professional training practice, representations.

* Magíster en Educación. Docente investigador de la Universidad Distrital Francisco José de Caldas. Correo electrónico: baquerorama@gmail.com

** Magister en Investigación Social Interdisciplinaria, docente investigador de la Universidad Distrital Francisco José de Caldas. Correo electrónico: villaw@hotmail.com 


\section{Introducción}

El estudio de las representaciones de la práctica de formación profesional, constituye una perspectiva de indagación sobre formación docente que, de manera específica, sitúa la pregunta por las prácticas o residencias como un momento crucial de la formación de maestros y maestras. Así mismo, este estudio apuesta por develar las dimensiones simbólicas y subjetivas del proceso, en el entendido de que dichas representaciones son factores determinantes para transformar las representaciones que pudiéramos denominar "hegemónicas de las prácticas docentes" y las propias representaciones de la profesión, elaboradas por los practicantes a partir de las cuales construyen sus identidades profesionales.

Con la pretensión de develar los aspectos simbólicos de la vida escolar, los estudios de las representaciones contribuyen a la comprensión más integral de las problemáticas de la formación, no solo porque sirven como mecanismos de evaluación de las acciones y discursos que forman a los maestros, y como dispositivos mismos de formación (Baillauquès, 2005), sino que tienen además un innegable valor político, por cuanto hacen visibles las voces muchas veces silenciadas de quienes se forman: su universo subjetivo y simbólico, sus sentimientos, imaginarios, expectativas, reclamos, satisfacciones y frustraciones con respecto a los componentes macrosociales e institucionales de la formación.

Dado el carácter abstracto y aún no consciente de las representaciones, es necesario considerar en términos de discurso las relaciones y pulsiones que se "encuentran entre lo íntimo del individuo y los datos externos -imagen personal y socializada-" (Baillauquès, 2005, p. 62). En estas, con frecuencia, se debate el "yo" que intenta representarse, máxime cuando sus producciones discursivas son inducidas. De allí que, para efectos del estudio, se consideren discursivamente tanto los datos que emergen de cuestionarios y entrevistas, como documentos institucionales, relatos de practicantes y producciones académicas de estos sobre el tópico de las prácticas. La pretensión es alcanzar tres objetivos específicos, a saber: 1) develar las representaciones sobre las prácticas pedagógicas de formación entre los profesores practicantes; 2) analizar las relaciones-tensiones (grado de coherencia) que operan entre dichas representaciones en relación con las finalidades que persiguen los programas; y 3 ) producir una teoría de rango sustantivo sobre las prácticas de formación docente en los programas de licenciatura. Siendo este último objetivo, la materia central de este informe.

\section{Las representaciones en la formación docente}

El problema de las representaciones, que parece atravesar todas las preocupaciones de la investigación social contemporánea, no es ajeno al campo de la educación, y particularmente a las propuestas de formación del profesorado. En cierto sentido, todas las propuestas de formación de profesores sustentadas o no en investigación, devienen representaciones sobre el oficio y sobre el proceso formativo que debe satisfacer las condiciones de un "modelo" de maestro y de habilidades o competencias inherentes a este. Aunque en nuestro medio pueden considerarse aún escasas las investigaciones que de manera explícita se interroguen por las formas como cada apuesta formativa se representa el oficio y la formación de los profesores, es cierto que toda propuesta de formación de docentes parte de unas representaciones o esquemas mentales que actúan como pautas para la organización de los currículos, y para el desarrollo y legitimación de acciones encaminadas a su formación.

Existe una especie de distanciamiento crítico entre las representaciones formales e institucionales que se construyen en torno al "deber ser" del proceso formativo y de la profesión, agenciadas en los programas institucionales (la selección de contenidos disciplinares y pedagógicos, las maneras de concebir 
y proyectar la formación investigativa de los practicantes, las formas de entender y proyectar los conocimientos disciplinares, la incorporación de los "nuevos saberes" que se demandan a los profesores en las instituciones escolares, etc.) y las representaciones derivadas de la experiencia de quien se forma cuando proyecta, en los escenarios de la práctica, los saberes constituidos en la tradición académica.

La cultura institucional de las escuelas parece determinar gran parte del comportamiento docente de los maestros practicantes (Davini, 1995, p. 79). Al aparato discursivo y a las prácticas pedagógicas universitarias parece contraponerse, de manera recurrente, el ambiente organizacional de la escuela. Algunas representaciones del practicante como intruso, transgresor, "cuidaniños", o de la práctica como ruptura, "servicio militar", requisito, lo real de lo imaginado o lo pensado en la academia, están asociadas a ese momento de encuentro entre el proceso formativo inicial y el ejercicio profesional, y, además, hacen visible que la formación del profesor, como señala Marta Souto (2009), no se reduce al tiempo de la universidad, no culmina en el momento del ejercicio profesional, no es una "trayectoria mecánica predeterminada", sino un trayecto que implica, entonces, el devenir, "el acontecimiento, como algo inédito, imprevisible, inesperado pero que sucede en el tiempo" (p. 18).

Eso que sucede en las prácticas hace posible la emergencia de representaciones que forman al nuevo maestro, más allá de los dispositivos académicos, y quizá configura comportamientos y actitudes docentes más duraderos que aquellos estructurados y adquiridos en la trayectoria del currículo universitario. De allí que las prácticas pedagógicas de formación y del ejercicio profesional propiamente dicho aparezcan, entonces, como el escenario privilegiado para el análisis de las representaciones sobre la formación y la carrera docente.
En ese sentido, el enfoque de las representaciones en la formación docente no es solo cuestión de investigación y evaluación curricular o un dispositivo de formación para hacer "maestros reflexivos", como lo propondrían Gilles Ferry (1998), Donald Schön (1992), Simone Baillauquès (2005), entre otros múltiples autores que podríamos considerar seguidores de la propuesta de Stenhouse (1987). También lo podemos considerar un poderoso dispositivo para poner en perspectiva política, situada en el sentido común de los actores sociales (maestros en ejercicio y en formación), la emergencia de representaciones de la formación y del oficio que resignifiquen el componente ético-político de la "acción educativa". Desde este habría que situar el problema de la reflexividad docente, más allá de la preocupación por la enseñanza eficaz y la excelencia académica, en el cuestionamiento profundo de la política educativa para la formación docente, en la que se instalan y producen los factores condicionantes de las prácticas: esos discursos que hacen hacer las prácticas de una manera determinada y que son fuente de las tensiones ya descritas.

Así entendidos, los estudios de las representaciones de la práctica docente como parte sustancial de la formación de profesores pueden contribuir a eliminar el malestar "de las culpas mutuas" entre universidad y escuela, cuando reducen el problema de la formación a la superación de las representaciones negativas del proceso, mediante la revisión de prácticas y contenidos declarativos que apuestan por una idea de profesionalización basada en la racionalización de conocimientos y por unas prácticas eficaces para satisfacer "demandas" de aprendizaje o formación de la escuela y de los maestros. Además, tales estudios permiten reposicionar la formación política de estos actores sociales, al hacerlos conscientes de que el factor que más determina la producción de representaciones de la formación y de la profesión opera por fuera del aparato discursivo de la universidad 
"Cuidaniños", intruso, mandadero: representaciones de la práctica de formación profesional

y de la escuela, en los marcos legales y de política pública que determinan, modifican e instauran discursos (Angenot, 2010) y prácticas que luego, el aparato escolar como campo de distribución y reproducción (véase Bernstein, 1993) debe legitimar, aun en contradicción con sus tradiciones formativas (discursos y prácticas) propias.

\section{Los estudios de la práctica desde el enfoque las representaciones}

Los estudios sobre las prácticas constituyen una parte importante de la investigación sobre formación docente. Aunque esta se ocupe de un amplio abanico de problemáticas que van desde los aspectos de orden curricular pedagógico y didáctico de la formación inicial y en ejercicio, hasta las políticas públicas para el sector, la pregunta por las prácticas es recurrente en las investigaciones sobre la formación de los maestros. De hecho, muchos de los interrogantes que se plantean sobre la formación docente se refieren, en realidad, a las prácticas que la constituyen.

¿Cuáles son los supuestos teóricos y los marcos de referencia para la formación de los docentes? ¿Cómo se diseñan, organizan y desarrollan dichos procesos y cómo se manifiestan en los currículos? ¿Quiénes son los sujetos de los procesos de formación docente y qué tipo de subjetividades se construyen con dichos procesos? ¿Quiénes son formadores y desde qué prácticas pedagógicas realizan esta labor? ¿Cómo construyen saber pedagógico? ¿Qué tipo de racionalidades orientan las prácticas formadoras de docentes? ¿A qué noción de escuela y de sujeto educativo responden dichas prácticas? Las anteriores, entre otras, son preguntas sobre formación docente que tocan la problemática de las prácticas, y particularmente las representaciones que las movilizan.

Un punto de partida y referencia obligada de los estudios de las representaciones de la práctica de formación de profesores, en el contexto latinoamericano, son los ya clásicos trabajos de Achilli, La práctica docente: una interpretación desde los saberes del maestro (1986), y de Edelstein y Coria, Imágenes e imaginación (1995), en el que las autoras sientan importantes bases teóricas para los posteriores estudios sobre las prácticas docentes de formación desde el enfoque de las representaciones. El punto de partida lo constituyen, por una parte, la pregunta por el sujeto de las prácticas: los practicantes y formadores frente al proceso institucionalizado de la práctica como ritual de iniciación; y por otra, el análisis de la condición estructurante de las prácticas en las identidades docentes.

En la reconstrucción crítica de las prácticas que proponen Edelstein y Coria, aparecen tres características dominantes que hoy, a veinticinco años de publicación de su obra, parecen vigentes. Se trata de los fenómenos de escisión, mimetización e impronta formal que caracterizan aún las manifestaciones de las prácticas y que llevan a producir cierto tipo de representaciones asociadas tanto a la "historia pedagógica" (el pasado escolar) del practicante, como al peso de los habitus (Bourdieu, 1997) en la trayectoria de la práctica misma.

La escisión es un fenómeno que no solo afecta los contenidos, el tiempo y la organización pedagógica de la formación, sino que compromete también cierta especialización del trabajo docente, entre quienes "enseñan" las disciplinas y quienes "enseñan a enseñarlas". La escisión no es solo entre teoría y práctica, sino también entre actores pedagógicos. La sola división del trabajo docente haría pensar que hay algo que cada especialista "ignora" de lo que hace el otro, con lo que se evidencia la inquietante paradoja de que entre quienes forman maestros unos saben enseñar "cosas", pero no saben cómo enseñar a enseñarlas, y otros quizá ignoren la naturaleza específica de esas cosas, pero tengan claves para "enseñar a enseñarlas". Quizá quepan otras interpretaciones posibles, por ejemplo, que a unos docentes universitarios 
encargados de la formación de los profesores para el sistema les cuesta más que otros, por razones de gusto, de formación o de imagen personal, acercarse a las escuelas, donde ocurren mayoritariamente las prácticas de formación. Lo que no puede desconocerse es que, cualquiera que sea la justificación, hay, en efecto, una fuerte disociación entre el trabajo en las aulas universitarias y el de las aulas de las escuelas y colegios, adonde acuden los practicantes a "ponerse en juego" como profesores.

Lo que podríamos inferir es que la universidad reproduce, desde la división misma del trabajo docente, las escisiones entre teoría y práctica que han caracterizado históricamente la formación del profesorado. Además, al establecer la dicotomía entre la formación teórica y la práctica, reproduce también un orden discursivo que ha actuado como dispositivo pedagógico de formación: por un lado, las habilidades y dominios declarativos y por otro lado, los dominios operativos. En el primero, las gramáticas disciplinares; y en el segundo, las destrezas operativas. Al primero corresponde la idea del trabajo intelectual; al segundo, la experticia basada en el dominio del método. No hay que olvidar que en la historia de la formación de los maestros la preeminencia de una u otra de estas macrovisiones de formación ha surtido efectos performativos, tanto en la construcción de identidades docentes como en los posicionamientos socioculturales de estos actores sociales (Zuloaga, 1999).

En cierto sentido, lo que se pone de manifiesto es la supervivencia de una idea de pedagogía reducida a la instrumentalización de la enseñanza y escindida de sus componentes políticos y sociohistóricos. Esto hace posible explicar-se la producción y distribución de los conocimientos (cualquiera que sea la disciplina) desde cierta asepsia ideológica, como si estos bienes simbólicos no constituyeran también formas específicas de saber-poder (Bernstein, 1993) y, por lo mismo, un asunto de pedagogía. La escisión está, entonces, en el centro de las construcciones teóricas disciplinares, a las que no escapa la teoría pedagógica, y mucho menos lo que intenta hacerse con ella en los centros de formación de profesores.

La mimetización e impronta formal, por su parte, pueden describirse grosso modo como las manifestaciones de la didactización de las aulas según el nivel de desempeño de la práctica (educación infantil, básica primaria o básica secundaria), para el caso de la mimetización; y como la instrumentación de las prácticas y la delimitación burocrática de la experiencia, sin superar la formalidad del "contrato pedagógico" entre institución formadora e institución de práctica, o entre practicante y profesor titular.

Resulta interesante analizar el fenómeno de la mimetización, porque desde nuestro punto de vista no se reduce al efecto que tiene la "didactización" de la clase en el tratamiento de los contenidos, particularmente en escenarios de práctica (por ejemplo el uso de carteleras, gráficos, definiciones, explicaciones, dibujos, consignas y, más recientemente, los recursos visuales electrónicos y multimedia, etc.), sino que también toca dimensiones más amplias que suelen arraigarse en los propios docentes.

La mimetización no solo opera en lo que Bernstein (1993) denominará exceso de producción significante sobre el significado, como característica básica de la recontextualización que sufre el discurso pedagógico, sino que además genera representaciones del saber disciplinar de los docentes, situadas en cierto reduccionismo definicionista instrumental, en el que queda atrapada la conceptualización de los fenómenos tratados en el aula, y que tiene, como correlatos las visiones que desvalorizan el trabajo docente, tan acentuadas en el imaginario social, y aun en los propios docentes, y los efectos de los principios de clasificación y enmarcación en las formas de control, 
tanto del conocimiento como de los actores educativos.

Desde la misma perspectiva, la denominada impronta formal hace que los acuerdos que rigen la llegada de practicantes a las instituciones escolares se reduzcan a "puntualizaciones de corte reglamentario [...] desde lo formal burocrático sin abrir instancias reales de encuentro entre instituciones y sujetos comprometidos en la experiencia; sin permitir el crecimiento mutuo por la socialización de los saberes analizados, discutidos y elaborados" (Edelstein y Coria, 1995, p. 14).

La impronta formal, pudiera decirse, es una suerte de reduccionismo de la pretensión pedagógica de la práctica al cumplimiento de las formalidades que establecen los convenios entre institución formadora e institución receptora de practicantes. Dentro de estas se encuentran la distribución de actividades a realizar, el número de horas dedicadas, la elaboración de diagnósticos e intervenciones en las aulas, el apoyo a las actividades extraacadémicas, etc. Lo que parece regir el desarrollo de la experiencia de la práctica es el cumplimiento burocrático de las acciones acordadas, sin ningún interés real en que la experiencia cumpla la función de dispositivo de formación.

\section{Metodología}

Para la realización del estudio se analizaron datos recogidos en cuatro programas de formación de licenciados de la Facultad de Ciencias y Educación de la Universidad Distrital de Bogotá. No hubo ningún criterio particular para la elección de estos, salvo la idea de ampliar el espectro de estudio de caso (Stake, 1998), hasta donde las posibilidades logísticas y de gestión de la investigación nos lo permitieran.

En relación con los datos se analizaron: un cuestionario con preguntas abiertas, aplicado a un grupo de 45 practicantes adscritos a cuatro programas académicos de licenciatura de la Universidad Distrital; seis entrevistas semiestructuradas; datos de conversaciones informales con practicantes y asesores; documentos sobre las prácticas existentes en cada programa estudiado; $y$ ponencias, relatos, documentos académicos y grupos de discusión recogidos durante el tercer encuentro de prácticas docentes, organizado por el equipo de investigadores en el programa de Licenciatura en Educación Básica con énfasis en humanidades y lengua castellana.

Para el análisis se utilizaron diversas herramientas, como el análisis de contenido (Sandoval, 1996); procedimientos de codificación, a partir de expresiones relevantes tomadas de las matrices semánticas construidas a partir de los datos; y elaboración de categorías apelando tanto a la tradición teórica constituida como a la emergencia de conceptos apoyada en los datos. No obstante el volumen de datos de diversa naturaleza, el tratamiento de estos se hizo a partir de la identificación de referencias y rasgos comunes (Sandoval, 1996), asociados a los conceptos de práctica y practicante como categorías básicas. Alrededor de estas giran los conceptos de dispositivos de formación, institución, normas, interacciones, etc.

\section{Resultados}

El análisis del corpus recogido para efectos de esta investigación permite la identificación de representaciones que pueden sintetizarse como sigue.

\section{La práctica es un espacio}

En un primer momento se identifica, por su recurrencia, una representación de la práctica como espacio físico y temporal, cuya demarcación no es sin embargo espacial sino predicativa, en el sentido de que es lugar de prueba, confrontación, experimentación, enfrentamiento, reconstrucción, vivencia, 
aprendizaje etc. Estas acciones se matizan mediante atributos que las evalúan desde distintos órdenes discursivos: empíricos, epistemológicos, axiológicos, etc. (plana, complicada, fácil, conductista, traumática, lineal, difícil, necesaria, enriquecedora).

El espacio de la práctica predicado como prueba, enfrentamiento o experimentación reproduce, por ejemplo, una representación dominante que muestra la distancia entre el proceso de formación inicial (el de las aulas universitarias) y el de la llegada al aula de clase escolar para "hacerse cargo de la enseñanza”. Este último momento aparece entonces como el verdadero, lo real de la formación. Frente al espacio imaginado de la formación teórica, la práctica parece desdibujar todo el bagaje conceptual sobre el aula: "un espacio en constante reconstrucción que se presta para probar metodologías distintas según las exigencias de cada contexto, a tal punto que incluso las exigencias puedan superar y revaluar la teoría”.

Afirmaciones como esta, que son recurrentes en los datos recogidos con instrumentos diversos, visibilizan una representación de la práctica semejante al laboratorio al cual se va a experimentar una teoría.

Por el contrario, cuando el diseño curricular del programa incorpora la práctica desde el comienzo del proceso formativo, las representaciones que surgen entre los practicantes predican tipos de acciones asociadas con la vivencia, el aprendizaje, la reconstrucción y la transformación de saberes y prácticas.

La práctica pensada como vivencia, intercambio, aprendizaje y espacio para la reflexión sugiere escenarios y posibilidades de representación distintos de las lógicas del experimento, la prueba y la confrontación. La búsqueda de correlaciones entre representaciones y enfoques teórico-metodológicos, así como de los criterios de administración en cada proyecto, terminó por mostrarnos relaciones estrechas entre lo que se predica de la práctica entre los practicantes y las formas de trabajo pedagógico y de administración de estas. En el mismo orden discursivo, caben las referencias a la práctica como exploración, apropiación, búsqueda, espacio de acercamiento, acciones que suponen una actitud abierta para el aprendizaje $y$, en todo caso, una valoración positiva y constructiva de la experiencia.

Las representaciones en las que la práctica aparece como espacio de sometimiento son más comunes entre los practicantes que la llevan a cabo solo al final de la carrera y durante dos breves periodos académicos. Y aunque en este caso resulte muy difícil establecer correlaciones directas entre tiempo de duración de la práctica y formación de una consciencia reflexiva, es interesante señalar que quienes viven durante más tiempo la experiencia de la práctica en el proceso formativo suelen cuestionar menos este espacio de formación. Haría falta en este sentido una nueva investigación que pudiera desentrañar si esas representaciones "menos conflictivas" son resultado de comprensiones más profundas de la práctica y su relación con la academia y con la profesión, o si, por el contrario, revelarían procesos de acomodacióninteriorización del universo escolar y sus lógicas tan cuestionadas de burocratización, isomorfismo e impronta formal, ya explicitadas en este documento.

\section{La práctica es un requisito}

Otra representación que aparece sobre la práctica, aunque no con la misma fuerza que la anterior, es la que la señala como requisito. En este caso se hace manifiesta la percepción burocrática de la formación y el peso de las determinaciones normativas sobre el interés y la vivencia. Se trata de una representación que predica el cumplimiento, el sinsentido y la rapidez (burocratización de la práctica) como condiciones dominantes sin que se revele ningún valor formativo. Excepto en el enunciado que la reconoce como un requisito necesario, es decir, no impuesto sino como condición para asegurar los vínculos entre 
teoría y práctica, esta traduce viejas representaciones asociadas al peso de la burocratización y la formalidad que, según se indicaba, persisten en el imaginario individual y colectivo de los practicantes, a pesar de las transformaciones discursivas que se movilizan en los programas de formación sobre los enfoques y finalidades de la práctica.

\section{La práctica es un choque}

Otra de las referencias comunes a la práctica es la que la considera como un choque. Esta representación reúne una gran variedad de predicados sobre la práctica y el practicante, que manifiestan las tensiones entre subjetivo / objetivo, teoría / práctica, sujeto / poder, etc. (véase Davini, 1995). Es la imagen mediante la cual el practicante se representa el enfrentamiento consigo mismo, con la autoridad del currículo, del maestro titular, de los asesores, normas, dispositivos y demás agentes de poder. El choque como metáfora despliega una amplia gama de sentidos que se abren tanto en valoraciones positivas como negativas de la experiencia.

Para quienes entienden la práctica en su valor formativo, el choque es, sobre todo, acontecimiento. Tiene un valor epistemológico y existencial. Es el enfrentamiento del sujeto consigo mismo, antes que con el orden establecido. En este orden discursivo, la imagen del choque con la práctica es oportunidad, aprendizaje, experimentación, reflexión y transformación. En sentido contrario, el choque es conflicto de poder, es lucha por el posicionamiento propio en relación con "lo otro" (discursos, sujetos e instituciones), por lo cual es ruptura, dominación, sometimiento y falacia.

En la primera configuración de sentidos, el choque de la práctica, en tanto representación positiva, puede hacer posibles las transformaciones del habitus, pues "provoca" una actitud reflexiva que modifica conductas y comportamientos naturalizados al descentrar el universo conceptual y actitudinal de quien así se representa la práctica. Por el contrario, en el segundo orden discursivo quizá sea constante el reforzamiento de actitudes e imaginarios negativos, que fácilmente pueden desplazarse hacia la burocratización, la mimetización y la asimilación temprana de la cultura institucional en su rostro desfavorable: el "shock de la práctica", e incluso el abandono definitivo de la profesión; o, lo que resulta más grave aún, la asimilación del trabajo docente con una mentalidad de funcionario.

Enunciados como "hay un choque entre las teorías que nosotras vemos porque obviamente nosotras no tenemos los contextos que, digamos, tenía Piaget; nosotras no trabajamos con los hijos de ningún brillante" permiten suponer $-\mathrm{y}$ allí radica la apuesta interpretativa de estos datos- que la carga de conocimientos declarativos está puesta en la gran teoría pedagógica y didáctica, y no en la lectura particular de los contextos educativos en los que el practicante desarrollará luego su ejercicio profesional. Esa carencia de formación sociopolítica es la que, justamente, provoca la imagen de choque o ruptura. Además, pone de relieve que las teorías pedagógicas y didácticas no pueden formularse como una gran teoría ignorando los contextos sociopolíticos, económicos y culturales en los que se producen. Aplicarlas en contextos fuertemente diferenciados por estos factores no solo constituye una forma de colonialismo epistémico, sino que también produce representaciones deficitarias sobre cognición, aprendizaje, desarrollo, etc., que perpetuán la dependencia y las formas de dominación simbólica.

En otro sentido leemos los enunciados que se refieren directamente a la experimentación metodológica en el aula, como el siguiente:

[...] cuando uno hace un proyecto, cuando uno piensa un proyecto, uno idealiza muchas cosas, los objetivos son simples ideales. Entonces, cuando tú 
lo pones en la práctica con ellos, cuando tú te das cuenta que, digamos, [...] no, no son los que uno creía, que tu actividad no es tan potente como tú la consideras.

Lo que parece ponerse en escena es una dimensión reflexiva, un tipo de reflexividad situada en la experimentación para hacer funcionar la enseñanza, que no necesariamente está interesada en la lectura del contexto socioeducativo, sino en la efectividad del método a la manera del profesional reflexivo de Schön (1992), Perrenoud (2005), entre otros. Si bien esta dimensión es necesaria para asegurar la calidad de la enseñanza, corre el riesgo, como ya lo han advertido sus críticos (Duarte, 2003; Lozano, 2011), de instrumentalizar la reflexión solo para el dominio técnico. En este caso, la idea de choque corresponde más a la lógica del desequilibrio cognitivo propio de los constructivismos psicológicos que a la percepción del choque como asunto de distribución y enmarcación, es decir, como un asunto de poder.

Los otros enunciados asociados para este análisis a la idea de choque remiten a las relaciones de poder: la lucha por el reconocimiento de sí, en tanto sujeto docente frente a la autoridad y dominio del profesor titular; la confrontación consigo mismo, en cuanto construcción de proyecto de vida; y la confrontación entre perspectivas críticas de la formación y la cultura institucional de los espacios de práctica. Estos tres órdenes de discurso, aunque referidos a la práctica como choque, revelan mejor los fenómenos de subjetivación del practicante. Ya no se refieren tanto al espacio pedagógico y didáctico de la práctica, como estructura y parte del currículo, sino a los efectos que esta produce en la construcción de sí del practicante, en interacción con los "otros" y "lo otro" que deviene, indiscutiblemente, en relaciones de poder. Por esta razón, integramos el análisis de esta representación a la de la figura del practicante, que se muestra en el siguiente apartado.

\section{Los avatares del practicante}

Las manifestaciones discursivas que los practicantes expresan de sí abren un amplio abanico de representaciones que recogen distintos tipos de prácticas, relaciones e interacciones. Muchas de estas corresponden a imágenes ya constituidas y analizadas en las investigaciones precedentes (Achilli, 1986; Batallan, 1983; Devalle, 2009; Jiménez y Perales, 2007), que ponen de manifiesto las tramas del sujeto en relación consigo mismo, con las instituciones y con los otros. En el fondo se trata de los desplazamientos y reubicaciones de sí frente a las relaciones de poder que instauran los distintos tipos de interacciones, actores y prácticas.

El análisis de las representaciones sobre la figura de sí, en tanto que practicante, muestra de manera recurrente una identidad fraccionada entre la figura del aprendiz de maestro, el secretario del profesor titular, el "cuidaniños", el intruso, el profesor en formación y una amplia gama de atributos que tanto dicen de los quiebres del practicante en sus relaciones con los otros (sujetos e instituciones), como de sus propias imágenes del proceso formativo. Lo que se lee en los datos revela las tensiones que vive entre los conocimientos declarativos con los que llega al aula de clase (la formación teórica) y su eventual escenificación (la práctica), así como con el tipo y naturaleza de la interacción que teje con los otros (sujetos e instituciones). En este contexto descubre o se hacen evidentes para él las lógicas del sometimiento, la instrumentalización de su figura, sus limitaciones de saber y hacer en el aula, pero también las condiciones de posibilidad, las responsabilidades y las oportunidades de la experiencia.

La sistematización del cuestionario predica aspectos que tocan de manera tangencial la figura del practicante y que muestran dos órdenes de discurso. El primero remite a las acciones propias de la experiencia y que suponen la conjunción de voluntad y deseo: 
encontrar-se, actuar, acercar-se, empezar a conocer, aprender del contexto, mostrar-se, poner a prueba, vencer miedos, evaluar-se, acompañar. El segundo indica sometimiento, obligación, aspectos enfatizados mediante una amplia gama de atributos, como los que revelan los datos obtenidos del cuestionario: observador ajeno, secretario, mandadero, etc. Estos constituyen apenas el abrebocas de unas imágenes de sí capturadas con instrumentos más abiertos, como los conversatorios, las narrativas y las producciones académicas de los practicantes, que revelan que esa identidad del yo practicante se ordena y reordena "sobre el trasfondo de las experiencias cambiantes de la vida diaria y de las tendencias fragmentadoras de las instituciones modernas" (Giddens, 1997, p. 236) en las que se debate el sujeto. De acuerdo con este autor, dichas tendencias implican además las tensiones entre unificación frente a fragmentación, impotencia frente a apropiación, autoridad frente a incertidumbre, experiencia personalizada frente a experiencia mercantilizada. Esta lectura, situada en el discurso que estudiamos, nos resulta, si no exacta, particularmente sugerente para analizar las representaciones de sí de los practicantes de maestros.

Podemos advertir, por ejemplo, qué aspectos causan una u otra representación de sí, de la práctica y del proceso formativo, de manera que no solo resulta posible identificar los atributos con los que se representa ("cuidaniños", mensajero, secretario, etc.), sino también las circunstancias y factores particulares en las que dichas representaciones emergen. Esto pone de relieve aspectos quizá invisibles como las interacciones, las normas y la cultura escolar, los enfoques metodológico-didácticos, los vacíos conceptuales, etc., como determinadores de las imágenes que construye el practicante.

Vivir la práctica docente constituye para muchos estudiantes de licenciatura en educación una situación de discordancia con la experiencia construida durante el proceso formativo, tanto porque las teorías sobre la escuela, la enseñanza, la educación, las disciplinas etc. no encajan con las "realidades de la práctica”, como porque las imágenes de sí como estudiante universitario (autónomo, crítico, libre, espontáneo) se confrontan con las del mundo laboral. Este resulta fuertemente jerarquizado. diferenciado $y$ enmarcado en relaciones de poder y subordinación, sustancialmente distintas a las de la vida en las aulas universitarias, en las que en muchos casos parecen diluirse las "ensoñaciones discursivas" de la formación teórica.

Las construcciones discursivas del practicante como sujeto que se representa, leídas desde las tensiones del yo (Giddens, 1997), a las que acudimos para analizar en detalle las representaciones del practicante y que desarrollamos ampliamente en el informe general de esta investigación, permiten mostrar que lo tensional-contradictorio de cada relación dialéctica (unidad / fragmentación, impotencia / apropiación, autoridad / incertidumbre, etc.), parece resolverse, justamente, en la vía de la aceptación del orden de las prácticas. No advertimos, en efecto, en las manifestaciones discursivas de los practicantes tendencias que pudiéramos denominar patologizantes o deslegitimadoras de las propuestas de práctica. En efecto, como lo muestra la tabla 1 , son más dominantes los factores que integran que aquellos que fragmentan la experiencia.

Tabla 1

\begin{tabular}{|l|l|}
\hline \multicolumn{1}{|c|}{ Factores que fragmentan } & \multicolumn{1}{c|}{ Factores que integran } \\
\hline $\begin{array}{l}\text { La Percepción de "sometimiento a la autoridad" del titular } \\
\text { (autoritarismo). Falta de compromiso del titular. }\end{array}$ & $\begin{array}{l}\text { Relaciones horizontales. Responsabilidad y dinamismo } \\
\text { del titular en el aula de clase. }\end{array}$ \\
\hline
\end{tabular}




\begin{tabular}{|l|l|}
\hline \multicolumn{1}{|c|}{ Factores que fragmentan } & \multicolumn{1}{|c|}{ Factores que integran } \\
\hline $\begin{array}{l}\text { Ausencia de acompañamiento del asesor de prácticas. } \\
\text { Actitud de subordinación y sometimiento ante la institu- } \\
\text { ción escolar. }\end{array}$ & $\begin{array}{l}\text { Presencia permanente y acompañamiento del asesor. } \\
\text { Capacidad de negociación y defensa de los practicantes. }\end{array}$ \\
\hline $\begin{array}{l}\text { Discontinuidad y ruptura entre el discurso de la universi- } \\
\text { dad y el mundo escolar. }\end{array}$ & Acercamiento de la universidad a la escuela. \\
\hline $\begin{array}{l}\text { Prácticas burocratizadas de la escuela. Rigidez del } \\
\text { currículo. }\end{array}$ & $\begin{array}{l}\text { Compromiso escolar, apertura y trabajo responsable con } \\
\text { los estudiantes. }\end{array}$ \\
\hline $\begin{array}{l}\text { Imposibilidad de acción frente a las prescripciones de la la } \\
\text { norma (planes, contenidos, pautas de disciplina). Rigidez } \\
\text { y formalismo. }\end{array}$ & $\begin{array}{l}\text { Incorporación del contexto sociocultural del estudiante } \\
\text { al trabajo pedagógico del aula: currículo y programación } \\
\text { flexibles. }\end{array}$ \\
\hline Predominio de discursos y prácticas mercantilizadas. & $\begin{array}{l}\text { Fortalecimiento de la conciencia política y social de la ac- } \\
\text { ción educativa . }\end{array}$ \\
\hline $\begin{array}{l}\text { Pérdida de sentido, deslegitimación de la experiencia. } \\
\text { Burocratización. }\end{array}$ & $\begin{array}{l}\text { Recuperación de la conciencia reflexiva de base } \\
\text { ético-política. }\end{array}$ \\
\hline & $\begin{array}{l}\text { Características etarias de estudiantes y practicantes: per- } \\
\text { cepción de cercanía. }\end{array}$ \\
\hline
\end{tabular}

Fuente: elaboración propia

Esto tiene para nosotros un valor muy importante, porque pone de relieve el peso de lo institucional, la autoridad de la práctica como referente, que aun con las contradicciones descritas genera confianza e identidad. No obstante, se encuentran siempre latentes la pérdida de sentido, el riesgo de la acomodación oportunista, las simples lógicas de sobrevivencia, para mantenerse dentro de los límites impuestos por el orden establecido, lo cual sería desastroso en una institución que forma educadores. Si las representaciones de la experiencia se desplazan progresivamente hacia la pérdida de sentido, las conductas de quienes allí se forman no pueden ser distintas a las de la burocratización, la mimetización, la instrumentalización y la falsa conciencia de sí y del trabajo docente. Ello supondría un quiebre profundo del proyecto político de formación de educadores.

\section{Discusión de resultados y conclusiones}

Merecen destacarse algunos aspectos identificados en los trabajos pioneros de Edelstein y Coria (1995),
Davini (1995), Edelstein (2003) y Messina (1999), referidos al peso de la cultura escolar en la construcción y consolidación de representaciones sobre la formación y el oficio de profesor. Los datos analizados permiten corroborar, como señala Messina y reiteran Edelstein y Davini desde otros conceptos, como los de impronta formal y burocratización, que el currículo oculto es más fuerte que los contenidos. También, que contra las pretensiones transformadoras del discurso universitario, la escuela y la cultura escolar guardan aún profundas resistencias que difícilmente puede romper o transformar el profesor practicante, máxime cuando el asesor se pliega, presionado por las relaciones de poder que se instalan en la escuela, a las decisiones y actitudes de profesores titulares de curso, coordinadores y administrativos.

En el mismo sentido y siguiendo muy de cerca a estas autoras, quizá deba destacarse también que resulta imposible pretender la uniformidad de las prácticas, toda vez que se trata de un fenómeno complejo signado por los contextos de realización y atravesado 
por distintos órdenes discursivos y de poder, que acusan tensiones y contradicciones profundas. Frente a estas, sin embargo, se requieren esfuerzos comprensivos y organizadores muy grandes que, sin pretensiones homogeneizadoras ni totalizantes, permitan rescatar los horizontes de sentido de la formación docente en sus dimensiones cognitivas, volitivas, actitudinales y políticas.

La cultura institucional de las escuelas parece determinar gran parte del comportamiento docente de los maestros practicantes. $\mathrm{Al}$ aparato discursivo y a las prácticas pedagógicas universitarias parece contraponerse, de manera recurrente, el ambiente organizacional de la escuela. Esto, quizá, no fuese tan grave si la universidad como institución formadora contara con una política clara para el desarrollo de estos espacios de formación; pero la ausencia de una política de prácticas de la universidad - en particular de la Facultad de Ciencias y Educación-, que trace los lineamientos básicos para su organización, administración y desarrollo en cada proyecto académico, deja al garete la experiencia de las prácticas en las instituciones escolares.

La lectura y el análisis de los datos recogidos para esta investigación ponen en evidencia que este importante espacio de formación se organiza de manera independiente y aislada, sin responder a un horizonte de sentido distinto al que cada programa se traza para el efecto. No hay, en consecuencia, fundamentos epistemológicos, de diseño curricular y de administración de este espacio que respondan de manera consistente a un proyecto político de formación de maestros, desde el cual se hagan visibles las relaciones entre la teoría y la práctica (dominios disciplinares $v s$. saberes para la enseñanza), la naturaleza de las relaciones entre universidad y escuela, y el sentido de las prácticas de enseñanza en poblaciones escolarizadas, como parte sustantiva de la práctica docente, para lo cual se supone que forman los distintos programas de licenciatura de la universidad.
La universidad ha abandonado progresivamente la formación política de sus estudiantes de profesorado. Hay una gran ignorancia entre los practicantes sobre los temas de políticas públicas educativas. Habría que preguntarse cuál es el lugar que ocupa en la formación de los docentes la formación política frente a la sobredeterminación de los discursos de pretensión didáctica o disciplinares, concebidos de manera aséptica y totalmente desideologizados.

Existe, en muchos de los aspectos de la práctica, tanto de alcance teórico como de realización en los escenarios escolares, una excesiva idealización que sustenta una suerte de equilibrio eufórico. Esto hace pensar a los practicantes que "transformaran el mundo escolar para siempre", hasta que la llegada al aula los devuelve a la realidad. Entonces se redescubren como sujetos sujetados, restringidos y controlados en muchas de sus iniciativas de "invención" de la escuela, por el universo fuertemente regulado y controlado de la cultura escolar.

Es posible, como señalan como Rockwel y Ezpeleta (1983), revalorizar en perspectiva positiva las inevitables tensiones entre teoría y práctica que, articuladas al "trabajo de campo" que suponen las prácticas, permiten relaciones diferentes entre lo micro y lo macrosocial, y jalonan el pluralismo y la reflexividad como condiciones para la comprensión abierta y dinámica de la escuela y de la práctica docente.

\section{Reconocimientos}

La investigación "Representaciones de la práctica de formación profesional", de la cual se deriva el presente artículo fue desarrollada con el auspicio del Centro de Investigaciones y Desarrollo Científico de la Universidad Distrital Francisco José de Caldas, en el periodo 2010-2012. 


\section{Referencias}

Abric, J. C. (2001). Representaciones sociales: aspectos teóricos y metodología de las representaciones sociales. En J. C. Abric (dir.), Prácticas sociales y representaciones (pp. 11-32 y 53-74). México: Ediciones Coyoacán.

Achilli, S. (1986). La práctica docente: una interpretación desde los saberes del maestro. Buenos Aires: Cricso.

Alliaud, A. (2002). Los residentes vuelven a la escuela. Aportes desde la biografía escolar. En M. C. Davini (coord.), De aprendices a maestros. Enseñar y aprender a enseñar (pp. 39-78). Buenos Aires: Papers.

Angenot, M. (2010). El discurso social. Los límites históricos de lo pensable y lo decible. Buenos Aires: Siglo XXI.

Baillauqués, S. (2005). El trabajo de las representaciones en la formación de los maestros. En $\mathrm{La}$ formación del maestro profesional. Estrategias y competencias (pp. 55-105). México: Fondo de cultura económica.

Baquero, P. (2006, julio-diciembre). Práctica pedagógica, investigación y formación de educadores: tres concepciones dominantes de la práctica docente. Redalyc Actualidades Pedagógicas, 49. Recuperado el 17 de septiembre de 2011, de http:// redalyc.uaemex.mx/pdf/956/95604902.pdf

Baquero, P., Santos, D., Molano, M. y Pardo, A. (2006). La investigación en el aula en la universidad: Apuntes para una revisión crítica. En Prácticas pedagógicas universitarias: aproximaciones para su comprensión (pp. 55-91). Bogotá: Universidad de la Salle.
Bernstein, B. (1993). La construcción social del discurso pedagógico. Bogotá: Corprodic.

Bourdieu, P. (1997). El sentido práctico. Barcelona: Anagrama.

Davini, M., C, (1995). La formación docente en cuestión. Buenos Aires: Paidós.

Devalle de Rendo, A. (2009) La formación docente: según las representaciones de los futuros maestros. Buenos Aires: Lugar.

Duarte N. (2003). Conhecimento tácito e conhecimento escolar na formação do professor (por que Donald Schön não entendeu Luria). Educação y Sociedade (Campinas), 24 (83).

Edelstein, G. (2003). Prácticas y residencias: memorias, experiencias, horizontes. Revista Iberoamericana de Educación (Organización de Estados Iberoamericanos), 33.

Edelstein, G. (2011). Formar y formarse en la enseñanza. Buenos Aires: Paidós.

Edelstein, G. y Coria, A. (1995). Imágenes e Imaginación. Iniciación a la docencia. Buenos Aires: Kapelusz.

Ferry, G. (1998). Pedagogía de la formación. Novedades educativas. Buenos Aires: Facultad de Filosofía y Letras, Universidad de Buenos Aires.

Giddens. A. (1997). Modernidad e identidad del yo. Barcelona: Península.

Gimeno, J. y A. Pérez. (1993). Comprender y transformar la enseñanza. Madrid: Morata.

Jiménez, M. y Perales, J. (2007). Aprendices de maestros. La construcción de sí. México: Pomares, Universidad Pedagógica Nacional Coahuila. 
Lozano, I. (2011). La formación de docentes reflexivos: una lectura histórico-política en México. Congreso.inie.ucr.ac.cr/memoria/documentos/3

Messina, G. (1999). Investigación en o investigación acerca de la formación docente: un estado del arte en los noventa. Revista Iberoamericana de Educación (Madrid) 19, 22- 95.

Moscovici, S. (1986). Psicología social (vols. I y II). Madrid: Paidós.

Paquay, L. y Wagner, M. C. (2005). Formación continua y video formación: qué habilidades se deben priorizar. En L. Paquay et al. (eds.), La formación profesional del maestro (pp. 265-308). México: Fondo de Cultura Económica.

Perrenoud P. (2005) El trabajo sobre el habitus en la formación de maestros. Análisis de las prácticas y toma de conciencia. En L. Paquay et al. (eds.), La formación profesional del maestro. México: Fondo de Cultura Económica.

Rockwell, E. y Ezpeleta, J. (1983). La escuela: relato de un proceso de construcción teórica. Recuperado el 12 de abril de 2012, de www. juridicas.unam.mx/publica/librev/rev/nuant/ cont/42/.../cnt5.pdf

Saldarriaga, O. (2000). Oficio de maestro, saber pedagógico y prácticas culturales en Colombia: siglos XIX y XX. En Investigación educativa y formación docente (pp. 66-94). Bogotá: Universidad El Bosque.

Sandoval, A. (1996). Investigación cualitativa. Bogotá: Icfes, Ascun.

Sandoval, S, Garavito, D., Amador, R. y Delgado E. (2002). Maestro: contextos y horizontes en su formación profesional. En El oficio de Investigar. Educación y pedagogía frente a nuevos retos. Bogotá: Centro de Investigaciones Universidad Pedagógica Nacional (CIUP).

Schön, D. (1992). La formación de profesionales reflexivos: hacia un nuevo diseño de la enseñanza y el aprendizaje de las profesiones. Barcelona: Paidós.

Souto, M. (2009), Complejidad y formación docente. En J. E. Yuni (comp.), La formación docente. Complejidad y ausencias. Córdoba: Encuentro.

Stake, R. (1998). Investigación con estudios de casos. Barcelona: Morata.

Stenhouse, L. (1987). La investigación como base de la enseñanza. Madrid: Morata.

Zuloaga, O. (1999). Pedagogía e historia: la historicidad de la pedagogía. Las prácticas de enseñan$z a$, un objeto de saber. Medellín: Universidad de Antioquia. 